\section{HAIRS UPON THE TONGUE.}

\section{To the Editor of The Lancet.}

SiR,-In your Journal of last week, p. 359, I perceive a notice on the growth of hairs upon the tongue, quoted under the authority of the "Oesterreichische Medicinische Wochenschrift," and referred to by you as a statement unworthy of credit.

On the continent the belief in the occasional presence of hairs upon the tongue is by no means uncommon, and has for its sup. porters several distinguished names. Bichât in his "General Anatomy," enumerates, among the situations in which hairs are sometimes accidentally developed, the surfaces of mucous membranes, as of the stomach, the intestines, the bladder, and the gall-bladder. On the mucous lining of the latter organ he found on one occasion about a dozen hairs, implanted by their roots into the tissue of the membrane. Villerme, again, announces that hairs have been found on the tongue, and in the pharynx, the rectum, the uterus, and the vagina.

If we turn our attention to the structure of the mucous membrane we find that it is not organised for the production of hairs, and in this particular differs essentially from the exterual investment of the body, which, in every point of its surface, is endowed with hair-producing follicles. It would, perhaps, considering the close analogy subsisting between the mucous membrane and skin, be presumptuous to declare that the production of hairs by the mucous membrane is impossible; but we may safely affrm that such an event is highly improbable. Admitting these premises, we have no alternative but that of coming to the conclusion that Bichât and the other authorities on this subject have been deceived by the appearance of a something resembling hairs. And I think this the more likely to have been the case from the imperfect knowledge of the structure of the skin existing in the time of Bichât, and from the absence of the only satisfactory test in a case of this nature, the microscope. Indeed, there is sufficient reason to believe that at the period referred to, such a detinition as the following would have been amply characteristic of a hair:-A filament, hair-like in form and dimensions, cylindrical, uniform in diameter, adherent by one extremity to the surface of an organ; but your youngest reader must be aware that at the present day better proof is needed than such a defi. nition could embrace.

With the kind of case described by the Austrian periodical, I am very familiar, having had my attention drawn to the subject during some microscopic investigations, about seven years since, and having subsequently seen many similar cases. In a work published in 1838, I have referred to these hair-like tufts growing on the tongue, and I have there remarked, in respect of them, that "the cuticular sheaths" of the papillæ of the tongue " become enormously enlarged and leugthened in some fevers."* This is the real nature of these productions: they are epithelial sheaths of papillæ, grown to a length of half or three-quarters of an inch, cylindrical in form, and hair-like in appearance and general characters; indeed, with. out the aid of the microscope and recent knowledge on the mode of development of the epithelium, we might easily believe them to be hair's. A bout a year after my first ob. servation of these filamentary sheaths, I had the opportunity of conversing on the subject with Henle, who quite agreed in the views which I had taken of them, and mentioned that he had seen a similar appearance in the epithelium of the alimentary canal.

This explanation applies with equal force to the other mucous surfaces indicated by Bichât and Villermé, and is peculiarly suited to the case narrated in the Austrian hebdomadal, for as we there read the so called hairs " disappeared under the influence of an enetic," a phenomenon not at all consistent with the kind of connection main. tained between hair's and their papillæ, but quite in unison with the supposition of their being elongaied epithelial sheaths. I am, Sir, your obedient servant,

London, June $5,1843$.

Erasmus Wilson.

QUININE IN TRAUMATIC FEVER.

A CÁSE has lately occurred in the Hôpital des Eufans at Parjs, in which M. Guersant has employed, with entire success, the sulphate of quinine in the treatment after am. putation of both lower extremities. The patient, a poor boy, whose limbs had been frozen by exposure during a winter's night, and afterwards most injudiciously bathed in hot water, was brought to the hospital, the limb exlbibiting a discoloured spotty ap. pearance, and other symptoms of inci. pient gangrene. This condition in six days, notwithstanding the application $o$ : bark-poultices and bottles of hot water $t$ the extremities, so greatly increased as to render necessary an immediate amputatior of both legs. The operation was success fully performed, and with little suffering th the patient, who gradually recovered, thougl not without indications of considerable feve aud erysipelatous inflammation, both $c$ which were subdued by doses of sulphat of quinine, amounting to twelve grains in day. M. Guersant cites other cases, alsc in which he has employed the same med cine with success, in all of which the leac ing feature was purulent reabsorptionGazelte des Hôpitaux, March 14.

* Practical and Surgical Anatom: page 307. 